\title{
Universidade de São Paulo/Departamento de Botânica
}

\author{
TÍTULO: Ciclo reprodutivo de Diplusodon orbicularis Koehne (Lythraceae). \\ AUTORA: Renata Carmo de Oliveira \\ DATA: $\quad 10$ de fevereiro de 1992 \\ LOCAL: Departamento de Botânica/Universidade de São Paulo \\ NÍVEL: Mestrado \\ BANCA EXAMINADORA: Berta Lange de Morretes (orientadora) - IB-USP \\ Maria Emília M. Estelita - IB-USP \\ Jorge Ernersto A. Mariath - UFRS
}

\begin{abstract}
RESUMO: O presente trabalho descreve os aspectos estruturais do ciclo reprodutivo de Diplusodon orbicularis Koehne. O microsporângio segue o padrão básico de desenvolvimento. O endotécio é fibroso, as camadas médias são efêmeras e o tapete é glandular e binucleado sendo reabsorvido durante o desenvolvimento dos grãos de pólen. A microsporogênese é simultânea; os grãos de polén são prolatos a prolatos esferoidais. Os óvulos, de placentação basal, são anatropos, crassinucelados e bitegumentados. A micrópila é em zig-zag e delimitada por ambos os tegumentos. O desenvolvimento do saco embrionário segue o padrão Polygonum. O padrão de embriogênese não pode ser acompanhado devido as dificuldades no seccionamento do material. O endosperma é do tipo nuclear, tornando-se posteriormente celularizado. Nos estágios finais do desenvolvimento do embrião, o endosperma é totalmente reaborsorvido.
\end{abstract}

TÍTULO: Estudos taxonômicos dos subgêneros de Monnina Ruiz \& Pavon (Polygalaceae), baseados em espécies brasileiras e equatorianas.

AUTORA: Alina Freire Fierro

DATA: 14 de fevereiro de 1992

LOCAL: Departamento de Botânica/Universidade de São Paulo

NÍVEL: Mestrado

BANCA EXAMINADORA: Ana Maria Giulietti (orientadora) - IB-USP

Maria Cândida Henrique Mamede - IBT

Ariane Luna Peixoto - UFRJ

RESUMO: Monnina R. \& P. (Polygalaceae) consta de ca. de 180 spp., e se distribui nas regiões montanhosas americanas. Inclui ervas e arbustos, com inflorescências racemosas ou paniculadas, flores zigomorfas, sépalas laterais petalóides, pétala posterior carenada e fruto drupáceo ou samaroide. Monnina foi dividida em três subgêneros: Hebeandra, Monninopsis e Pterocarya, e depois foi reduzida a Monnina e Monninopsis. Para verificar a validade destas divisões infragenéricas, escolheram-se e estudaram-se 13 spp. Concluiu-se que o grupo deve permanecer ainda dividido nos três subg: Monnina inclui arbustos, com inflorescência congesta, sem nectários extra-florais, pétala posterior trilobada, estilete engrossado e fruto drupáceo e se dis-tribui nos Andes e América Central; Pterocarya, inclui ervas, com inflorescência laxa, com ou sem netários extra-florais, pétala posterior trilobada, estilete engrossado, fruto samaróide e se distribui principalmente no Sul, Sudoeste e Sudeste da América do Sul, podendo chegar até o Sul dos Estados Unidos. Monninopsis apresenta ervas, com inflorescência sublaxa, sem nectários extra-florais, pétala posterior tripartida, estilete filiforme e fruto samaróide ou drupáceo e se distribui disjuntamente no Nordeste brasileiro e no Mato Grosso. Avaliaram-se os resultados com análises fenéticas. Estudou-se também a fenologia de $M$. richardiana. 
TíTULO: Estudo da morfogênese in vitro em tecidos de Cuphea ingrata Cham. \& Schlechtd. e Cuphea ericoides Cham. \& Schlechtd.

AUTORA: Izulme Rita Imaculada

DATA: 21 de fevereiro de 1992

LOCAL: Departemento de Botânica/Universidade de São Paulo

NÍVEL: Mestrado

BANCA EXAMINADORA: Eny I. Segal Floh (orientadora) - USP

Miguel Pedro Guerra - UFSC

Gilberto B. Kerbauy - USP

RESUMO: Neste trabalho, foram estudados e estabelecidos os parâmetros básicos para a cultura de tecidos de Cuphea ericoides e Cuphea ingrata. cujas sementes apresentam como substância de reserva diversos ácidos graxos de cadeia média e triglicérides em quantidade e diversidade sem paralelo no reino vegetal. O estudo visa, primordialmente, a análise dos processos morfogenéticos, incluindo-se aspectos estruturais e micropropagação destes materiais. Os diferentes tipos de explantes (foliares, caulinares e medulares) foram cultivados em meio de murashige e skoog e vitaminas de nitsch, contendo diferentes balanços de reguladores de crescimento, na luz. As respostas morfogenéticas obtidas foram avaliadas e acompanhadas por estudos cito-histológicos. Dentre os principais resultados, destacam-se: a) presença de calo em praticamente todos os tratamentos, sendo indispensável uma auxina e uma citocinina no meio de cultura; b) raízes geotrópicas negativas, regeneradas de regiões internas dos calos, em C. ingrata: , c) neoformação de gemas, a partir de regiões superficiais do calo e de raízes, em C. ericoides; d) desenvolvimento das gemas e obtenção de plantas enraizadas de $C$. ericoides; e) presença de diferentes padrões de tecidos nos calos, os quais podem ser correlacionados ao aspecto morfológiço.

TÍTULO: Musgos acrocárpicos do Estado de Rondônia, Brasil.

AUTORA: Regina Célia Lobato Lisboa

DATA: 28 de fevereiro de 1992

LOCAL: Instituto de Botânica/Universidade de São Paulo

NÍVEL: Doutorado

BANCA EXAMINADORA: Adauto Ivo Milanez (orientador ) - IBt

Carlos Eduardo de M. Bicudo - IBt

Alcides Ribeiro Teixeira - IBt

Edison José de Paula - USP

Reinaldo Monteiro - UNESP-Rio Claro

RESUMO: Cinqüenta e seis táxons de musgos acrocárpicos, distribuídos por onze famílias de Bryidae, coletados no Estado de Rondônia, no Brasil, foram estudados taxonomicamente. Destas, Ephremeraceae e Phyllodrepaniaceae são referências novas para Rondônia. As sete subordens encontradas foram separadas por meio de chave, sendo tratadas isoladamente, contendo descrições e chaves de identificação para famílias, genêros e espécies. Cada táxon foi detalhadamente descrito e ilustrado, e contém dados sobre material examinado, distribuição geográfica, habitat, comentários taxonômicos e notas ecológicas. A família melhor representada, tanto pelo número de táxons (19), quanto pelo número de coletas (139), foi Calymperaceae. Foram observadas espécies raras, como Calymperes uleanum, Micromitrium thelephorothecum e outras. Quatorze táxons endêmicos para a região norte, quatro pantropicais, quatro neotropicais e dois cosmopolitas foram referidos. 
TítULO: Aspectos taxonômicos, anatômicos e econômicos da ipeca Pṣ̣chotria ipecacuanha (Brot.) Stokes (Rubiaceae).

AUTORA: Maria Camargo de Assis

DATA: 23 de abril de 1992

LOCAL: Departamento de Botânica/Universidade de São Paulo

NÍVEL: Mestrado

BANCA EXAMINADORA: Ana Maria Giulietti (orientadora) - USP

Antonio Salatino - USP

Hermógenes de F. Leitão Filho - UNICAMP

RESUMO: Psychotria ipecacuanha (Brot.) Stokes, é uma planta medicinal da família Rubiaceae, importante pela produção em suas raízes do alcalóide emetina. Neste trabalhọ foram feitas análises das três populações disjuntas que compõem a espécie e que ocorrem na América Central (Nicarágua, Costa Rica e Panamá), Colômbia, sul da floresta amazônica (Rondônia e Mato Grosso) e mata atlântica (Pernambuco até Paraná). No estabelecimento dos limites inter e intraespecíficos, foram utilizados todos os dados morfológicos vegetativos e reprodutivos disponíveis e feita análise dos componentes principais que permitiu concluir que não existem diferenças significativas entre as populações examinadas. As poucas diferenças individuais não estão relacionadas com a distribuição geográfica das populações examinadas. Como conclusão, a ipeca ao longo de toda a sua distribuição geográfica foi considerada como uma só espécie Psychotria ipecacuanha (Brot.) Stokes. Além da análise taxonômica, foram apresentados neste trabalho, dados anatômicos, do número de cromossomos e dados econômicos da espécie.

TÍTULO: Revisão taxonômica de Pilosocereus Byles \& Rowley (Cactaceae) no Brasil. AUTORA: Daniela Cristina Zappi

DATA: $\quad 8$ de maio de 1992

LOCAL: Departamento de Botânica/Universidade de São Paulo

NÍVEL: Doutorado

BANCA EXAMINADORA: Ana Maria Giulietti (orientadora) - USP

José Ruben Pirani - USP

Maria Cândida Henrique Mamede - IBt

João Semir - UNICAMP

Hilda Maria Longhi Wagner - UFRGS

RESUMO: Este trabalho visa colaborar para o conhecimento da taxonomia e evolução de Pilosocereus no Brasil, apresentando estudos morfológicos e fornecendo um tratamento taxonômico completo das espécies, possibilitando sua identificação aos níveis específico e infraespecífico. Foi realizado extensivo trabalho de campo, e a metodologia da taxonomia tradicional foi utilizada em associação com técnicas de estudo morfológico das sementes em scanning e análise cladística, utilizada para determinar o relacionamento entre as espécies e grupos de espécies. São apresentadas características para a taxonomia do gênero, úteis tanto a nível de revisão taxonômica e de análise filogenética como de florística. Pilosocereus localiza-se entre os gêneros mais plesiomórficos da tribo Cereeae, apresentando diversas simplesiomorfias comuns aos demais gêneros basais da tribo. As sinapomorfias utilizadas para delimiar o gênero são relacionadas a características dos frutos, que são depresso-globosos, deiscentes por fendas irregulares e polpa funicular alva ou colorida. Pilosocereus apresenta 38 espécies de distribuição nas Américas, e ocorrem no Brasil 29 espécies, das quais 27 foram tratadas em detalhe, sendo que duas, P. rupicola de Sergipe e P. oligolepis de Roraima, não receberam tratamento aprofundado, por serem insuficientemente conhecidas no Brasil. 
TÍTULO: Leucobryaceae (Bryopsida) do Brasil.

AUTORA: Olga Yano

DATA: 22 de maio de 1992

LOCAL: Departamento de Botânica/Universidade de São Paulo

NÍVEL: Doutorado

BANCA EXAMINADORA: Adauto Ivo Milanez (orientador) - IBt

Ana Maria Giulietti - USP

Kátia Cavalcanti Porto - UFPE

Noemy Y. Tomita - IBt

Flávio Augusto de Souza Beechez - USP

RESUMO: Leucobryaceae (Bryopsida) no Brasil contém 29 táxons, sendo uma espécie nova e 4 citadas pela primeira vez (*): Leucobrym albicans (Schwaegr.) Lindb., L. albidum (Brid. ex P. Beauv.) Lindb., L. bowringii Mitt., L. clavatum Hampe var. brevifolium Broth., L. crispum C.M., L. giganteum C.M., L. glaucum (Hedw.) Aongstr.*, L. juniperoideum (Brid.) C.M., L. laevifolium Broth.*, L. martianum (Hornsch.) Hampe, L. nilghiriense C.M.*, L. sordidum Aongstr., Ochrobryum gardneri (C. M.) Lindb., O. obtusifolium (C. M.) Mitt, O. stenophyllum Besch., Octoblepharum africanum (Broth.) Card., O. albidum Aedw., O. albidum Hedw. var. violascens C. M., O. ampullaceum Mitt., O. cocuiense Mitt., O. costatum Crum*, O. cylindricum Mont., O. erectifolium Mitt. Ex Williams, O. leucobryoides O. Yano (sp. nov.), $O$. pellucidum C. M., O. pulvinatum (D. \& M.) Mitt., O. rhaphidostegium C. M. ex Broth. e O. stramineum Mitt. São apresentadas descrições detalhadas, ilustrações, distribuição geográfica no Brasil e países da América do Sul e discussão de substrato. Foram colocados em sinonímia: Leucobryum goyazense Broth., L. megalophyllum (Raddi) Broth., L. megalophyllum var. minus Broth., L. brasilense C. M., Ochrobryum paulense Geh. \& Hampe, O. subobtusifolium Broth. e Octoblepharum fragillimum Aongstr. Leucobryum itacolumitis C. M., L. brevifolium C. M. non Bartram e L. crispellum C. M. são nomes de herbario.

TíTULO: Estudo morfológico e ontogenético de galhas foliares em pau-jacaré Piptadenia gonoacantha (Mart.) Macbr. (Fabales, Mimosaceae).

AUTOR: Marcos Arduin

DATA: $\quad 29$ de junho de 1992

LOCAL: Departamento de Botânica/Universidade de São Paulo

NÍVEL: Mestrado

BANCA EXAMINADORA: Jane Elizabeth Kraus (orientadora) - USP

Nanuza Luiza de Menezes - USP

Geraldo Wilson Fernandes - UFMG

RESUMO: Em folíolos de Piptadenia gonoacantha foram observadas galhas espinhosas com 3 ciclos anuais (90 dias cada). As galhas apresentaram 6 estágios de desenvolvimento. Externamente: 1) Observase uma pequena mancha no folíolo. 2) Forma-se, a partir desta, uma pequena projeção de cor vermelha. 3) Ocorre um aumento de tamanho do corpo da galha, formando-se espinhos curtos a sua volta e no ápice observa-se um tufo de espinhos mais longos. 4) O corpo da galha alonga-se, adquirindo uma forma cônica. 5) O crescimento cessa e os espinhos distribuem-se por igual. 6) Forma-se uma abertura no ápice da galha, por onde o indutor emerge. Internamente: 1) No parênquima neoformado observa-se uma loja revestida de esclereídes. 2) Este parênquima aumenta, definindo-se o córtex e a medula, que fica junto a loja. 3) Ocorre um aumento do córtex, seguido posteriormente de um aumento da medula; as esclereídes vão desaparecendo e instala-se o tecido nutritivo ao redor da loja. 4) A medula aumenta de tamanho e parte de suas células situadas acima da loja alongam-se. 5) Esclerificam-se as células na zona entre córtex-medula e o indutor 
consome as células medulares, passando depois a consumir as que ficam acima da loja, para construir o canal de saída rumo ao ápice da galha; finalmente o indutor volta a loja, onde se transforma em pupa. 6) $\mathrm{O}$ indutor atinge a fase adulta e emerge.

TítUlO: Estudos taxonômicos no gênero Xyris L. (Xyridaceae) da Serra do Cipó, Minas Gerais. Brasil

AUTORA: $\quad$ Maria das Graças Lapa Wanderley

DATA: 14 de agosto de 1992

LOCAL: Departamento de Botânica/Universidade de São Paulo

NIVEL: Doutorado

BANCA EXAMINADORA: Ana Maria Giulietti - USP

Nanuza Luiza de Menezes - USP

Graziela Maciel Barroso - JBRJ

João Semir - UNICAMP

Reinaldo Monteiro - UNESP-Rio Claro

RESUMO: A família Xyridaceae está representada na Serra do Cipó pelo gênero Xyris reunindo cerca de $27 \%$ das espécies brasileiras e $45 \%$ das espécies dos campos rupestres brasileiros. Vários aspectos foram abordados no presente trabalho como morfologia, anatomia da folha e do escapo floral, estudos fenéticos e de distribuição geográfica. Com base nos dados obtidos, foram reconhecidas 42 espécies, 4 variedades e uma subespécie. Uma seção, quatro espécies, uma variedade e uma subespécie novas foram descritas. Seis espécies foram sinonimizadas, duas espécies e duas variedades foram restabelecidas. Prováveis híbridos foram reconhecidos entre X. longiscarpa Alb. Nilsson e $X$. itatiayensis (Malme) Wanderley. Foram reconhecidas cinco áreas de maior concentração das espécies de Xyris no Brasil destacando-se a Cadeia do Espinhaço e a Serrạ Geral de Goiás, onde ocorrem cerca de 93 espécies, sendo 63\% endêmicas, consideradas como dois centros de diversidade do gênero Xyris. Cinco padrões de distribuição geográfica foram reconhecidas para as espécies da Serra do Cipó, incluindo desde espécies de ampla distribuição até espécies endêmicas para a região.

TÍTULO: Perfil flavonóidico de espécies de Cuphea P. BR. (Lythraceae)

AUTORA: Deborah Yara Alves Cursino dos Santos

DATA: $\quad 16$ de dezembro de 1992

LOCAL: Departamento de Botânica/Universidade de São Paulo

NIIVEL: Mestrado

BANCA EXAMINADORA: Maria Luiza Faria Saletino (orientadora) - USP

José Rubens Pirani - USP

João Batista Fernandes - UFSC

RESUMO: Foram analisadas as composições flavonoídicas de 16 espécies de Cuphea P. BR. com a finalidade de fornecer informações úteis para a taxonomia do grupo. Os flavonóides extraídos das folhas foram isolados e identificados através de técnicas cromatográficas e por espectrofotometria de uv/visível. Trinta e cinco flavonóides foram isolados e identificados. A maioria são flavonóis 3-Q-Glicosídeos, derivados de canferol, quercetina, ramnetina, isoramnetina e mitricetina; mais raramente foram encontrados derivados de apigenina e luteolina. O perfil flavonóidico parece ser útil como marcador taxonômico a nível específico, uma vez que os flavonóides variam de espécie para espécie. Além disso, se mostrou promissor no auxílio de uma futura revisão para o gênero e no estabelecimento de suas relações inter e intraespecíficas. 
TítUlo: Desmidioflorula do Lago Novo Andira (Rio Acre), Estado do Amazonas.

AUTORA: Maria Roselia Marques Lopes

DATA: $\quad 21$ de dezembro de 1992

LOCAL: Departamento de Botânica/Universidade de São Paulo

NÍVEL: Mestrado

BANCA EXAMINADORA: Carlos E. de M. Bicudo (orientador) - IBt

Célia Leite Sant'Anna - IBt

Estela Maria Plastino - USP

RESUMO: O trabalho é parte do inventário taxonômico das algas de um lago marginal do Rio Acre, Lago Novo Andira, Estado do Amazonas, a partir de 52 amostras coletadas durante 14 meses consecutivos (maio/88-junho/89). Foram identificados 98 táxons sendo 88 espécies, 37 variedades e 5 formas taxonômicas, dos quais 53 constituem a primeira citação para o Estado do Amazonas. Os gêneros mais bem representados foram Cosmarium, Closterium e Stçurastrum e os menos representados foram Arthrodesmus, Gonatozygon e Xanthidium. Além da descrição detalhada, são fornecidos para cada táxon estudado a referência a descrição original, o basiônimo (quando existente), comentários taxonômicos, a distribuição geográfica no Estado do Amazonas e, no mínimo; uma ilustração. A distribuição geográfica foi feita com base em toda a literatura publicada até dezembro/9l e foram considerados tanto os trabalhos mais completos, com descrições e/ou ilustrações, quanto aqueles nos quais constam apenas listagens. O trabalho é ilustrado por um mapa com a localização da área de estudo e 227 ilustrações dos táxons identificados.

TítUlO: $\quad$ Anatomia dos órgãos em desenvolvimento de Musa rosacea Jacq. (Musaceae).

AUTOR: Yedo Alquini

DATA: $\quad 4$ de fevereiro de 1993

LOCAL: Departamento de Botânica/Universidade de São Paulo

NÍVEL: Doutorado

BANCA EXAMINADORA: Berta Lange de Morretes (orientadora) - USP

Maria Emília M. Estelita - USP

Therezinha Paviani - UNB

Sílvia Rodrigues Machado - UNESP-Botucatu

Walkyria R. Monteiro - USP

RESUMO: Realizou-se análise dos aspectos anatômicos dos órgãos em desenvolvimento de Musa rosacea Jacq. (Musaceae). Estudos em termos de microscopia fotônica, microscopia eletrônica de varredura e microscopia eletrônica de transmissão foi efetuado, quando necessário, nos diferentes órgãos da planta em questão. Análise do processo de vascularização floral também foi efetuada. Uma análise em termos de comprimento e largura das fibras, nos diversos órgãos da planta, foi realizada. Um estudo enfocando a porcentagem de compostos fenólicos em diversos órgãos da planta, foi efetuado. A porcentagem de tanino, foi feita, apenas em relação aos frutos, em diversos estádios de desenvolvimento.

TíTULO: Caracteres anatômicos e ultrestruturais dos órgãos vegetativos de Mandevilla illustris (Vell.) Woodson e M. velutina (Mart. ex Stadelm.) Woodson - Apocynaceae.

AUTORA: Beatriz Appezzato da Glória

DATA: $\quad 4$ de fevereiro de 1993

LOCAL: Departamento de Botânica/Universidade de São Paulo

NÍVEL: Doutorado 
BANCA EXAMINADORA: Maria Emília Maranhão Esteliita (orientadora) - USP

Berta Lange de Morretes - USP

Luiz Antonio de Souza - UFLon

Sílvia Regina Machado - UNESP-Botucatu

Walter Handro - USP

RESUMO: O presente estudo visa fornecer informações sobre a anatomia e a ontogênese dos órgãos vegetativos de Mandevilla illustris e de M. velutina com o objetivo de acrescentar dados a anatomia da família Apocynaceae, destacando os caracteres de valor taxonômico. Os espécimes procedentes de uma área de campos cerrados da estação experimental de Itirapina (SP), são distinguíveis entre si pela morfologia floral e do sistema subterrâneo. Este último caracteriza-se por um xilopódio seguido por uma raiz tuberosa. A ontogênese deste sistema revela diferenças entre os indivíduos quanto a estrutura anatômica do xilopódio, resultantes da variação da altura de tuberização. O intumescimento da raiz tuberosa inicia-se na região de ramificação da raiz primária e progride acropetamente podendo alcançar a região de transição vascular até a base do hipocótilo. O crescimento da raiz tuberosa enquadra-se nos padrões anômalos. A análise anatômica do caule aéreo e folha revela que não existem caracteres de valor diagnóstico. Ocorrem três estruturas secretoras: coleteres, laticíferos e idioblastos. Os coleteres são analisados quanto a estrutura, ocorrência, ontogênese, secreção e ultra-estrutura. Os laticíferos são não articulados, porém ocorre um sistema secundário de laticíferos a partir do câmbio vascular.

TítUlO: Revisão taxonômica de Pteris L. (Pteridaceae) no Brasil

AUTOR: Jefferson Prado

DATA: 5 de fevereiro de 1993

LOCAL: Departamento de Botânica/Universidade de São Paulo

NÍVEL: Doutorado

BANCA EXAMINADORA: Paulo Gunter Windisch - (orientador) UNESP-São José do Rio Preto

Ana Maria Giulietti - USP

Estela Maria Plastino - USP

João Semir - UNICAMP

Hermes Moreira Filho - UFPR

RESUMO: O presente trabalho trata do estudo taxonômico das espécies de Pteris L. (Pteridaceae) ocorrentes no Brasil. Foram reconhecidas 24 espécies e 2 variedades, sendo que as assinaladas a seguir com um asterisco são exclusivamente brasileiras: $P$. longifolia $\mathrm{L}$., $P$. vittaia $\mathrm{L}$., $P$. cretica $\mathrm{L}$., multifida Poir., P. pungens Willd., P. plumula Desv., P. deflexa Link, P. congesta J. Prado $\left({ }^{*}\right)$, P. biaurita L., P. leptophylla SW (*), P. schwackeana Christ (*), P. splendens Kaulf. P. grandifolia L., P. haenkeana Presl. P. limae Brade, P. lechlert Mett., . decurrens Presl., P. propingua Ag., P. pearcei Baker, $P$. brasiliensis Raddi, $P$. denticulata SW. var. denticulata, $P$. denticulata var. tristicula (Raddi) J. Prado, $P$. angustata (Fée) Morton (*), P. altissima Poir. e P. podophylla SW. São apresentados um status novo para Pteris tristicula Raddi $=P$. denticulata SW. var. tristicula $($ Raddi) $\mathrm{J}$. Prado e um nome novo para $P$. gracilis Fée $=P$. congesta $\mathrm{J}$. Prado, além de várias sinomizações. Foram reconhecidos 3 padrões básicos de distribuição geográfica para as espécies estudadas e um centro secundário de diversidade e endemismo para Pteris. São apresentadas chaves para identificação das espécies e variedades, descrições, ilustrações, dados e mapas de distribuição geográfica, além da análise de caracteres importantes na taxonomia a nível de reconhecimento do gênero, espécies e variedades. 
TÍTULO: Compostos e linhagens para o cultivo de cogumelos comestíveis: Agaricus spp.

AUTORA: Ana Cristina Bolãnos Rojas

DATA: 19 de abril de 1993

LOCAL: Departamento de Botânica/Universidade de São Paulo

NÍVEL: Mestrado

BANCA EXAMINADORA: Vera Lúcia R. Bononi (orientadora) - IBt

Sérgio Teixeira da Silva - USP

Sonia Machado C. Dietrich - IBt

RESUMO: São apresentados os dados de cultivo de seis linhagens dos cogumelos Agaricus bisporus (Lanje) Unbach, A. bitorquis (Quél.) Sacc e Agaricus sp. Quatro compostos diferentes foram usados como substratos. Os cultivos foram feitos em condições controladas (Jaguariuna, SP) e em condições não controladas (Mogi das Cruzes), onde a maioria dos cogumelos são cultivados no Brasil. Sob condições não controladas o composto baseado em bagaço de cana-de-açúcar com esterco de galinha ou cavalo, apresentou os melhores resultados, e as linhagens mais produtivas, foram duas de Agaricus bisporus. Em condições controladas, palha de arroz com esterco de cavalo, foi o composto mais produtivo e quatro linhagens de Agaricus bisporus foram as mais produtivas e superiores inclusive aquelas de condições não controladas. Além dos compostos, também atuam na produção, as condições ambientais (temperatura, umidade relativa a $\left(\mathrm{Co}_{2}\right)$

TÍTULO: Morfologia, desenvolvimento e anatomia de Tubebuia caraiba (Mart.) Bur. - Bignoniaceae AUTORA: Amélia Vera Guimarães de Sousa

DATA: $\quad 7$ de maio de 1993

LOCAL: Departamento de Botânica/Universidade de São Paulo

NÍVEL: Doutorado

BANCA EXAMINADORA: Berta Lange de Morretes (orientadora) - USP

Cesar Martins Chagas - IB

Marília Morais Castro - UNICAMP

Walkyria R. Monteiro - USP

Maria Emília E. Maranhão - USP

RESUMO: Esta pesquisa contém dados sobre o eixo vegetativo, analisado sob o ponto de vista do desenvolvimento morfológico e anatômico de Tabebuia caraiba (Mart.) Bur. - Bignoniaceae, espécie arbórea freqüente no cerrado de Emas, Pirassununga, Estado de São Paulo. As sementes, coletadas no local e cultivadas em solo de cerrado e mantidas em condições ambientais da cidade de São Paulo, permitiram observar o desenvolvimento morfológico e anatômico da espécie até a idade de 4 anos. Nas plantas adultas foram observados: época de florada, desenvolvimento dos elementos florais, do fruto e da semente. Anatomicamente foi estudado o eixo vegetativo: raiz, região de transição, hipocótilo, epicótilo, folha cotiledonar e nomofilo de espécimes jovens e adultos. Constatou-se a presença de xilopódios e raízes gemíferas. Foi estudada a anatomia do lenho e da casca da raiz e dos caules subterrâneo e aéreo; verificouse que os três tipos de lenho podem apresentar placas de perfuração foraminadas. Observou-se a capacidade de rebrotamento de plantas em condições naturais e a formação de calo em raiz e caules subterrâneo e aéreo. Foram estudados: a organização das folhas cotiledonares e nomofilos, os estômatos, tricomas e nectários.

TÍTULO: Extração de eliciadores de fitoalexinas de fungos do filoplano de Rubiáceas nativas. AUTORA: Ana Paula Pimentel Costa 
DATA: $\quad 16$ de junho de 1993

LOCAL: Departamento de Botânica/Universidade de São Paulo

NÍVEL: Mestrado

BANCA EXAMINADORA: Sonia M. Campos Dietrich (orientadora) - IBt

Sergio Teixeira - USP

Maria Luiza F. Saletino - USP

RESUMO: Muitas plantas respondem a microorganismos patogénicos ou não patogénicos através do acúmulo de fitoalexinas - compostos de baixo peso molecular que inibem o crescimento de microrganismos - moléculas que induzem o acúmulo de fitoalexinas nas plantas são chamadas de eliciadores. Dois fungos Penicillium steckl (saprobio) e Colletotrichum gloeosporioides (patogênico) os quais ocorrem naturalmente no filoplano de rubiáceas nativas, foram estudados quanto a sua capacidade indutora e de produção de moléculas eliciadoras. Foram estabelecidas as condições ótimas de produção e atividade destes eliciadores para Penicillium steckl e as melhores condições foram para culturas com 10 dias de idade, suspensões de 107 esporos/ml e a extração dos eliciadores foi através da autoclavagem da suspensão de esporos $\left(5 \mathrm{~min} .21{ }^{\circ} \mathrm{C}\right)$ para $C$. gloeosporioides estabeleceu-se como ideais culturas com 15 dias de idade, suspensão de 107 esporos/ml, e extração dos eliciadores por solubilização a frio, sem agitação, através do fracionamento por filtração em gel. Foi verificado que as moléculas eliciadoras apresentam peso molecular heterogêneo variando de 500 a 30.000 dáltons. As propriedades destes eliciadores sugerem que estes devam ter uma natureza glicoprotéica. A análise dos resultados indicou que não havia uma correlação direta entre a atividade indutora e patogenicidade. A atividade indutora parece estar mais relacionada com a resistência ou não da planta ao microrganismo invasor do que com o hábito do fungo (sapróbio ou parasita) ou as características estruturais das moléculas eliciadoras.

TíTULO: Perfil favonóidico de espécies das seções Carphocephalus Koern. e Dimorphocaulon Ruhl. de Syngonanthus Ruhl. (Eriocaulaceae).

AUTORA: Carla Valéria Ricci

DATA: 18 de junho de 1993

LOCAL: Departamento de Botânica/Universidade de São Paulo

NÍVEL: Mestrado

BANCA EXAMINADORA: Maria Luiza F. Salatino (orientadora) - USP

Marie-Anne Van Sluys - USP

Wagner Vilegas - UNESP-Araraquara

RESUMO: As Eriocaulaceae constituem uma família natural, neotropical com sérias dificuldades taxonômicas, principalmente a nível genérico e abaixo dele. O presente trabalho relata a distribuição dos flavonóides em 18 espécimens distribuídos em 13 espécies das seções Carpocephalus Koẻrn. e Dymorphocaulon Ruhl. de Syngonanthus Ruhl. com o objetivo de trazer novas evidências para a taxonomia do gênero. Os flavonóides foram extraídos com MEOH $80 \%$ e isolados por meio de cromotografia preparativa em papel com BAW e ácido acético $15 \%$. Técnicas cromotográficas e espectométrica visível foram usadas para a identificação dos compostos. Vinte e quatro flavonóides foram encontrados, a maioria deles 7-0glicosídeos de luteolina e 6-hidroxiluteolina. Este trabalho representa o primeiro relato desta substância para as Eriocaulaceae. Os resultados mostram uma afinidade entre Syngonanthus e Leiothrix devido a presença de O e C- glicoflavonas em ambos. Por outro lado Syngonanthus é distinto de Eriocaulon e Paepalanthus, pois estes gêneros são caracterizados principalmente por flavonóis. A nível seccional) nenhuma diferença foi observada entre Carpocephalus e Dymorphocaulon. Entretanto, essas seções são ditintas de Eulepis e Thysanocephalus pois nestes táxons faltam glicosídeos de liuteolina 6-hidroxilada e 
apresentam freqüentemente C-glicosídeos de luteolina. C-glicosídeos são raros nas espécies de Carpocephalus e Dymorphocaulon e até agora somente derivados de apigenina foram encontrados nas espécies destas seções. Esses resultados concordam com evidências derivadas da morfonatomia. Os resultados deste trabalho mostram a utilidade dos flavonóides como marcadores taxonômicos em Syngonanthus e sugerem a utilização destes compostos para uma possível revisão do gênero.

TíTULO: Efeitos de fontes nitrogenadas sobre o desenvolvimento, teores hormonais endógenos, perfis polipeptídios $\mathrm{c}$ isoenzimáticos em três espécies de bromélias cultivadas in vitro.

AUTORA: Helenice Mercier

DATA: 22 de junho de 1993

LOCAL: Departamento de Botânica/Universidade de São Paulo

NÍVEL: Doutorado

BANCA EXAMINADORA: Gilberto B. Kerbauy (orientador) - USP

Rita de Cássia L. Figueiredo Ribeiro - IBt

Lilian B. P. Zaidan - IBt

Antonio Peters - UFPelotas

Antonio Salatino - USP

RESUMO: Estudou-se a influência de fontes nitrogenadas inorgânicas e orgânicas sobre o desenvolvimento de 3 espécies de bromélias cultivadas in vitro, Pitcairnia flammea, de hábito terrestre; Vriesea philippocoburgii, epífito com tanque e Tillandsia pohliana, de hábito atmosférico. Tomaram-se como parâmetros os teores endógenos de aba, aia e citocininas, bem como os perfis polipeptídicos, isoenzimáticos e os teores de nitrogênio orgânico, íon amoniacal livre e compostos fenólicos. A presença de nitrato de amônio ou d-glutamina mostrou-se vantajosa ao desenvolvimento das 3 espécies. As fontes de nitrogênio afetaram quantitativamente de modo distinto cada um dos genotipos utilizados. Em relação às citocininas, observou-se uma predominância das formas IP e IPA sobre as do tipo Ze ZR, independente do tratamento e da espécie. Foram detectados polipeptídeos com PM similares aos das subunidades grandes e pequenas da rubisco, além de polipetídeos possivelmente constituintes das proteínas ligadas às clorofilas B. As enzimas desidrogenase glutâmica e aspartato aminotranferase foram detectadas nas 3 espécies, sendo que algumas fontes nitrogenadas influenciaram o padrão isoenzimático.

TíTULO: Contribuição ao estudo da regulação da atividade do elemento de transposição AC do milho em Arabidopsis thaliana (L.) Heynh (Cruciferae)

AUTORA: Kátia Castanho Scortecci

DATA: 18 de setembro de 1993

LOCAL: Departamento de Botânica/Universidade de São Paulo

NÍVEL: Mestrado

BANCA EXAMINADORA: Marie-Anne Van Sluys (orientadora) - USP

Sonia M. C. Dietrich - IBt

Sergio Olavo Pinto da Costa - USP

RESUMO: Neste trabalho foram caracterizadas as seqüências metiladas no interior de AC em 21 plantas transgênicas de Arabidopsis thaliana analisadas individualmente. Os sítios do par de isoesquizômeros HPAIl e MSPI encontram-se na região 5' líder do mRNA, sendo que os resultados obtidos coincidem com os encontrados para AC em plantas de milho. Acredita-se que a presença de metilação seja responsável pela inativação do elemento $\mathrm{AC}$ no genoma de $A$. thaliana. Na tentativa de associar a metilação caracterizada em AC e nos T-DNAs com a atividade do elemento, realizou-se um tratamento com agente 
desmetilante 5 azacitidina. O tratamento com 5' AZAC foi feito com doses consideradas subótimas a nível fisiológico. As condições utilizadas para este não promoveram alterações significativas a nível de germinação e nem a nível de desenvolvimento. Além disso, estas não foram suficientes para diminuir o nível de metilação em AC e nos T-DNAs. Observamos também que $A$. thaliana apresentou uma baixa sensibilidade a este agente, uma vez que foram utilizadas concentrações elevadas da droga quando comparada a outros sistemas como tabaco, arroz e petúnia. Analisando o DNA de plantas tratadas com o agente desmetilante, observamos que este não diminui o nível de metilação do elemento AC e T-DNAs introduzidos. Verificamos também que houve um aumento importante da metilação nas plantas S3 (295) estudadas.

TíTULO: Hyphomycetes associados à folhas em decomposição de Alchornea triplinervia (Spreng.) M. Arg. e Euterpe edulis Mart.

AUTORA: Rosely Ana Piccolo Grandi

DATA: $\quad 14$ de outubro de 1993

LOCAL: Departamento de Botânica/Universidade de São Paulo

NÍVEL: Doutorado

BANCA EXAMINADORA: Vera Lucia R. Bononi (orientadora) - IBt

Eurico Cabral Oliveira Filho - USP

Adauto Ivo Milanez - IBt

Alcides R. Teixeira - IBt

Walderez Gamballi - USP

RESUMO: Estudaram-se os hyphomycetes presentes em folhas em decomposição de Alchornea triplinervia (Spreng) M. Arg. e Euterpe edulis Mart. foram dados: caracterização genérica, discussão genérica, caracterização das espécies, comentários das espécies e distribuição geográfica mundial para cada táxon encontrado. Os espécimes obtidos foram comparados quanto a ocorrência sobre o folhedo das plantas mencionadas, pelo índice de similaridade de sorensen e apurada baixa similaridade. O folhedo foi coletado de junho de 1988 a junho de 1990 na Reserva Biológica do alto da Serra de Paranapiacaba, que representa trecho de mata atlântica. Aplicou-se ao folhedo a técnica da lavagem sucessiva com água destilada esterilizada e manutenção dos fragmentos foliares em câmaras-úmidas. Lâminas permanentes foram depositadas no herbário do Instituto de Botânica (SP). Os seguintes táxons constituem primeira citação para o Brasil: Chalara alabamensis, C. microspora, Chloridium transvaalense, C. virescens var. caudigerum. Cryptophiale kakombensis. Dactylaria candídula, Dendrosporomyces splendens, Dicranidion fragile, Dictyochaeta novae-guineensis, Diplococcium stoveri, Gonytrichum chlamydosporium var. chlamydosporium, Sporidesmium bambusicola, S. leonense, S. parvum e Thozetella cristata. Os hyphomycetes "dematiaceous" predominaram em ambos os substratos. Ao todo 37 táxons foram identificados, sendo E. edulis a planta com maior riqueza em fungos.

TíTULO: Distribuição flavonóidica das Seções Eulepis Bong. e Thysanocephalus Koern. e a taxonomia de Syngonanthus Ruhl. Eriocaulaceae.

AUTORA: Márcia C. Pereira Bonfim

DATA: $\quad 5$ de novembro de 1993

LOCAL: Departamento de Botânica/Universidade de São Paulo

NÍVEL: Mestrado

BANCA EXAMINADORA: Maria Luiza F. Salatino (orientadora) - USP

Ana Maria Giulietti - USP

Elenice Mouro Varande - USP-Ribeirão Preto 
RESUMO: As Eriocaulaceae constituem um grupo natural, embora com taxonomia complexa. Trata-se de uma família característica das monocotiledôneas, de distribuição pantropical, cujo maior número de espécies encontra-se na América do Sul, em especial nos campos rupestres do Brasil. Sỵngonanthus Ruhl. É o terceiro maior gênero em número de espécies da família. Os perfis flavonóidicos de 10 espécies pertencentes as seções Eulepis Bong e Thysanocephalus Koern de Syngonanthus foram analisados com o objetivo de caracterizar tais espécies, visando contribuir na elucidação de problemas taxonômicos para o gênero através da química dos flavonóides. A extração, purificação e identificação das substâncias foi realizada através de técnicas cromatográficas e de espectrometria de uv-visível. Foram isolados 32 flavonóides em sua maioria $o$ - e $c$-glicosídeos de luteolina, além de $o$ - e $c$-glicosídeos de apigenina e $6 \mathrm{O}$ $\mathrm{H}$ luteolina. Os principais açúcares encontrados foram glicose e galactose, sendo a ocorrência de xilose significativa. Embora arabinose tenha sido o glicosilante de menor ocorrência, ele foi importante por se apresentar apenas na forma diglicosídica em membros da seção Eulepis e Thysanocephalus e se mostraram de certa forma bastante homogêneas quanto ao perfil flavonóidico, caracterizando-se e diferenciando-se de Carpocephalus e Dimorphocaulon. Esta homogeneidade também foi observada em trabalhos morfoanatômicos.

TíTULO: $\quad$ O gênero Paepalanthus Kunth - Seção Actinocephalus Koern. (Eriocaulaceae) na Serra do Cipó, Minas Gerais, Brasil - Taxonomia e Fenologia.

AUTOR: Paulo Takeo Sano

DATA: $\quad 26$ de novembro de 1993

LOCAL: Departamento de Botânica/Universidade de São Paulo

NÍVEL: Mestrado

BANCA EXAMINADORA: Ana Maria Giulietti (orientadora) - USP

José Rubens Pirani - USP

Maria do Carmos E. do Amaral - UNICAMP

RESUMO: É apresentado o levantamento das espécies da seção Actinocephalus Koern. (Paepalanthus, Kunth, Eriocaulaceae) na Serra do Cipó, Santana do Riacho, MG, Brasil. A seção Actinocephalus incluí 43 espécies, tendo sido encontradas 9 na Serra do Cipó $P$. cipoensis Silveira, $P$. denudatus Koern, $P$. diffusus Silveira, $P$. heterotricahs Silveira, $P$. hilairei Koern, $P$. polyanthus (Bong.) Kunth, $P$. ramosus (Wikstr.) Kunth, P. robustus Silveira, P. tuberculatus Silveira, $P$. spirifer foi sinonimizada em $P$. polyanthus nesse trabalho. Foram estudados materiais de herbários, feitas viagens mensais à região para coletas e observações fenológicas de $P$. hilairei, $P$. polyanthus e $P$. robustus. São apresentadas chaves de identificação, descrições e ilustrações das espécies, com comentários sobre distribuição geográfica e observações de campo. Enquanto $P$. denudatus, $P$. hilairei, $P$. polyanthus e $P$. ramosus apresentam distribuição mais ampla, $P$. cipoensis, $P$. diffusus, $P$. robustus e $P$. tuberculatus são endêmicos na Serra do Cipó. Detectou-se que $P$. hilairei e $P$. robustus são perenes e $P$. polyanthus é bianual. Em todas as espécies verificou-se um período de floração concentrado nos meses de verão. A dispersão se dá com manutenção dos escapos em $P$. hilairei ou queda dos mesmos, em $P$. polyanthus e $P$. robustus.

TíTULO: Anatomia e embriologia de Miconia cabucu Hoehne 1933 - (Melastomataceae - Miconiae) AUTOR: João de Deus Medeiros

DATA: $\quad 14$ de dezembro de 1993

LOCAL: Departamento de Botânica/Universidade de São Paulo

NÍVEL: Doutorado

BANCA EXAMINADORA: Berta Lange de Morretes (orientadora) - USP 


\author{
Célia Massa Beltrate - UNESP-Rio Claro \\ Maria Emília M. Estelita -USP \\ Silvia Rodrigues Machado - UNESP-Botucatu \\ Terezinha Sant'Anna Melhem - IBt
}

\begin{abstract}
RESUMO: Constitui o objetivo deste trabalho a realização de um estudo morfo-anatômico e embriológico de Miconia cabucu, árvore heliófila pioneira típica das formações secundárias da floresta ombrófila densa. O estudo morfo-anatômico compreendeu a caracterização da estrutura dos diferentes órgãos da planta. A plântula é faneroepigea e os cotilêdones apresentam venação actinodroma perfeita reticulada suprabasal. A lâmina foliar apresenta estrutura dorsiventral, é hipoestomática, com epiderme simples e estômatos diacíticos. A epiderme abaxial é completamente recoberta por tricomas estelares, ferrugíneos. A venação é acródroma suprabasal perfeita. A raiz é poliarca com periciclo estratificado. Os pelos radiciais são ramificados e septados. O caule do tipo pseudosifonostelico diferencia feixes medulares anficrivais, endoderme com estrias de caspary e periciclo. A madeira é clara com discretos anéis, a textura é fina e grãdireita. As placas de perfuração são simples e as pontuações alternadas e ovais, casca persistente e fissurada, inflorescência terminal e monotélica, flor perfeita. A citocinese na cmp é simultânea e as tétrades tetraédricas, pólen prolato tricolporado e tripseudocolpado, tétrade de megasporos linear e o calazal funcional. O gametofito feminino é Polygonum com antípodas efêmeras, endosperma nuclear, embriogênese Solanacea e semente não-endospérmica, dispersa por formigas.
\end{abstract}

TÍTULO: Filogenia de Porphyra spp. (Rhodophyta) seqüenciamento do gene nuclear para o RNA da subunidade pequena do ribossoma (rDNA 185) e estudos morfológicos da fase conchocelis.

AUTORA: Mariana Cabral de Oliveira

DATA: 16 de dezembro de 1993

LOCAL: Departamento de Botânica/Universidade de São Paulo

NÍVEL: Doutorado

BANCA EXAMINADORA: Edison José de Paula (orientador) - USP

Marilza Cordeiro Marino - IBt

Marie-Anne Van Sluys - USP

Pio Colepicolo - USP

Itamar R. Garcia Ruéz - USP

RESUMO: Porphyra apresenta uma grande importância econômica, sendo cultivada em fazendas marinhas para alimentação. O gênero tem mais de 70 espécies e é amplamente distribuído. Para esclarecer a taxonomia e a filogenia de Porphyra foram utilizadas metodologias de biologia molecular e a fase conchodelis do ciclo de vida. Verificou-se que a conchocelis pode ser usada para complementar os estudos taxonômicos do gênero. Através do seqüenciamento do rDNA 185 foram construídas árvores filogenéticas que mostraram que o gênero Porphyra é monofilético e é bastante primitivo dentro das algas vermelhas (Rhodophyta). Entre os eucariontes, Porphyra divergiu ao mesmo tempo que o nucleomorfo de Cryptomonas. $\mathrm{O}$ alto grau de divergência genética encontrada entre espécies de Porphyra, além de indicações do registro fóssil sugerem que o gênero é bastante primitivo. Durante a análise filogenética, foi detectada a presença de um intron pertencente ao grupo I no rDNA 185 de algumas espécies de Porphyra. Esse intron apresentou variantes geográficos de tamanho em 3 populações de $P$. spiralis var. amplifolia. $\mathrm{O}$ variante maior desse intron é capaz de auto-processamento ("self-splicine") in vitro. 